\title{
PRODUCTIVITY AND QUALITY : A STRATEGY FOR THE SA DEFENCE FORCE
}

BY REAR-ADM R.EBERLEIN*

\section{INTRODUCTION}

In recent times the SA Defence Force (SADF) has been bombarded with a variety of methods and approaches to the improvement of productivity, financial savings and, most recently, for quality of work life or quality assurance.

Various approaches have included the concepts of Total Quality Management (TQM), Quality Circles (and variants in the guise of Triads and others), Methodology, Unit Management Systems, Cost Control Systems, Deterministic Productivity Accounting and the like.

There have been many benefits to be found in these various approaches, each of which concentrates on certain aspects of productivity.

That there have been great achievements in productivity in the SADF is a matter of record, a record which is reflected in a National Award for Productivity, a smaller more efficient SADF, and a reputation for submitting more recommendations for improvements than other departments in the Public Service. At a more personal level though, the writer has gained the impression that no or very little attempt has been made to integrate selected aspects of these approaches into an overall "productivity" strategy acceptable to the SADF.

That there is a need for such an overall strategy is clear from the sentiments expressed recently by the members of the SADF's Productivity Co-ordination Committee when attempting to indicate the way ahead to even greater productivity in the SADF (Meeting, January 1991).

In this paper a strategy for the improvement of productivity and the quality of work life which is acceptable to the SADF is proposed.

\section{FACTORS AFFECTING PRODUCT- IVITY IN THE SADF}

AIMS OF THE SADF

In a recent paper (Eberlein 1990:35) the link between the (then) four aims of the Chief of the SADF (CSADF) and the characteristics of a successful organisation were identified. These aims have subsequently been reduced to two viz:

Win the War and

Effective Management, with the remaining two being seen, quite correctly, as results of the other. A good public image and high morale are therefore inherent in the two remaining aims.

Logically speaking any effort to improve productivity or quality of work life should in itself focus on the achievement of these aims, and at the same time contribute to the SADF continuing to be a successful organisation. "Successful" used in this context is taken to mean both effective and efficient in achieving its aims and objectives (van Dyk, 1987:17) This term includes the meaning ascribed to "Excellence", a term also popular in the literature (Peters and Waterman, 1982:8).

\section{THE CONCEPT OF PRODUCTIVITY}

Productivity as defined by Callahan et al (1986:506) and as accepted by the SADF is:

"The ratio of output to input" or in other terms:

Productivity = Output/Input

$=$ Results Achieved/Resources

Consumed

There appear to be two basic approaches to productivity. The first and seemingly very popular approach is 
the "Technology and Capital" approach which concentrates on the improvement of work methods and the use of technology and capital in improving work performance (Callahan et al, 1986:506).

The second, typified by the work of Sutermeister (1969:5) concentrates on the human aspects of productivity, emphasising that all the capital and technology in the world will not improve productivity if the human factor is ignored. The truth lies somewhere between the two approaches ie one which takes into account the need for truth lies technology and capital, but which acknowledges the vital role played by "the most important single element" in achieving productivity.

\section{QUALITY OF WORK LIFE}

Quality of work life ( $Q W L$ ) means that one receives psychic personal satisfaction from the work as well as economic reward (Lehrer, 1983:304). QWL is a highly individualistic matter, but there appear to be some common dimensions applicable to all individuals, which relate to concepts of human dignity and self-fulfilment which in themselves are related to the hierarchy of human needs as propagated by Maslow and the Motivation-Hygiene theory of Herzberg (ibid:308).

The changing characteristics of the work force of the SADF have been dealt with separately (Eberlein, 1990:30) and changes occurring in the individual regarding attitudes to the organisation; personal needs and job commitment, social values, motivation needs and so on. These changing characteristics determine the degree to which aspects of $Q W L$ become meaningful to each individual.

These changing characteristics also affect the way in which productivity improvement is tackled. There appears to be a widespread need among individuals for involvement, commitment and supporting interpersonal relationships in the work situation. This means that the culture of the organisation, its management and leadership styles, its personnel philosophy and regulations, its reward system and related aspects need to be developed so that commitment, productivity and QWL are possible.

Culture change in an organisation is a long-term process. To change from a "Role Culture" such as that of the SADF to one more supportive of the changing needs of the individuals in the SADF could take between 6 and 15 years (Eberlein, 1990:32).

\section{QUALITY ASSURANCE}

Quality Assurance (QA) (as typified by the Toyota KANBAN system in Japan) is seen as being at the heart of the postwar success story of that country (Cronje et al 1987:324). In essence it requires reliable quality and reliable delivery of products. In the KANBAN system Toyota succeeded in increasing the quality and reliability of their products to the extent that very little stockpiling of supplies was needed. At the same time the delivery time for one of these vehicles was reduced to seven days, compared to the three to eight weeks common in South Africal(ibid). The effect of $Q A$ on productivity is selfevident.

\section{JOB PERFORMANCE}

Over the years, theorists have observed that productivity, regardless of how it is defined, is a function of both the individual's ability and his motivation to perform. Mathematically, ability times motivation equals job performance:

\section{Ability $\times$ Motivation $=$ Job Performance}

Ability refers to the individual's prior training, experience and education (McAfee and Poffenberger, 1982:3).

Motivation on the other hand refers to the desire of the individual to perform well, and is related to the following factors: (Sutermeister, 1969:vii)

a. Social conditions: In this are included aspects such as: Organisation structure; Leadership style and climate; personnel policies; communication; and the informal organisation.

b. Individual needs: Which are related to education, experience, training, cultural back-ground and so on. 
c. Physical conditions: The physical conditions under which the individual performs his job.

The relationship between motivation and morale is depicted by the following primary conditions for high morale (CSADF Pamphlet, 1988):

a. Leadership: As part of management, seen as the ability to influence people to work together willingly. Management includes leadership as well as planning, organising and control (Cronje et al, 1986:115)

b. Communlcation: Providing the necessary news, information and feedback needed for the individual to perform his job successfully.

c. Administration: Interpreting and implementing the rules and regulations relating to the wellbeing and recognition of the individual.

d. Training and Development: The provision of the training,education and experience needed by the individual for successful performance of his job.

e. Working conditions: The physical environment in which the work is performed.

\section{PRODUCTIVITY AND INDUSTRIAL RELATIONS}

Ehlers (Sake-rapport, 1991:10) makes it clear that there is a very definite relationship between industrial relations (IR) and productivity. He emphasises that in order to improve productivity managers will have to:

a. improve their communication with the work force;

b. develop and implement participative management styles;

c. develop and apply fair and reasonable manpower policies and procedures;

d. formulate and apply a management philosophy and policy which is supportive of productivity improvement:

e. change from a negative to a positive approach in implementing manpower policies and practices; and f. strive for the achievement of a common vision and overall aims and objectives.

\section{CULTURAL ACCEPTABILITY}

Although many would argue to the contrary, experience has proven that any solution to a problem encountered in the SADF must be culturally acceptable. The SADF has a distinct culturelanguage which, although somewhat adulterated by misuse and the addition of non-cultural slang, attaches distinct meanings to certain words and tends to reject words and concepts which do not fall within that cultural frame of reference. The use of socalled "civilian" theories and concepts or those from a "foreign" culture eg the United States of America, as a solution or part of a solution makes their rejection much more likely. By way of example terms such as "management", "corporate strategy", "employee empowerment" and the like may raise the hackles of SADF personnel (Eberlein, 1990:36).

A strategy for productivity in the SADF ought therefore to be framed in and use terms and concepts culturally suited to the organisation.

\section{ONGOING PRODUCTIVITY PRO- GRAMMES}

Several productivity programmes are presently in use in the SADF, each attuned to the needs and cultures of the Arms of Service and Staff Divisions. In this way the Navy has developed a Triad system and a development programme which is aimed at easing the trauma of the recent large scale downsizing of the Navy. The Air Force has a programme which includes a great deal of culture change and the integration of productivity into that culture. In the Medical Services an attempt is being made to integrate productivity into the daily functioning of the service.

Each of these programmes has developed to a different stage and each has its advantages and disadvantages. Any strategy developed for the SADF as a whole should therefore take the ongoing programmes into account, should preferably enhance them and, 
where necessary, redirect their efforts to more nearly conform with the overall SADF requirements. Any attempt to negate the efforts already put into these programmes and force them to start "from square one" as it were, is doomed to failure.

Although it is difficult to provide factual evidence in support of the following statement, in the opinion of the writer the term "productivity" and the programmes associated with productivity have developed a somewhat adverse connotation in the SADF, primarily as a result of the (unconscious) association thereof with retrenchment and financial stringency. In addition, for very much the same reason, it can be argued that "ownership" of productivity programmes and consequently involvement in them has been restricted to a few members of the SADF.

Although there is no doubt that the SADF is very much a professional armed force, attempts have and are continuing to be made to enhance the degree of professionalism both of the force and of its members.

In pursuance of this a recent classified study made certain recommendations concerning the composition of the SADF, and more recently Project DYSAN (1989:VI-1) defined the professional nature of the military practitioner. This term was used for the first time to emphasise the professional nature of the military calling. The military practitioner is expected first and foremost to be a professional militarist and secondly an expert in the application of his specialist (or functional) knowledge and skills in the military milieu (ibid:V-22).

\section{CRITERIA FOR A SUCCESSFUL PRODUCTIVITY STRATEGY}

\section{CONTINGENCY APPROACH}

For many years organisations have been searching for the "one" productivity strategy to which all can adhere and which will solve all the problems of productivity for once and all. Fortunately or unfortunately, there is no such thingl(McAfee and Poffenberger, 1982:5).

There are three basic assumptions or principles that need to be accepted before setting up a strategy for productivity:

a. No single approach for improving productivity will be effective under all conditions.

b. Most approaches presently available will be effective under certain conditions.

c. Under certain conditions one or more approaches could be just as effective as another (ibid).

The contingency approach therefore assumes that in implementing the strategy various approaches to the solution of problems arising will be found by the implementers, according to the conditions pertaining in the organisation at the time.

\section{ORGANISATIONAL CRITERIA}

An in-depth study of the characteristics of organisations associated with high productivity and success indicated the following criteria were necessary for success in this area (Lehrer, 1983:343):

a. Top management commitment and Involvement: The conviction that productivity can be managed, and that the example in this must be set by top management.

b. Formalised: The formal inclusion of productivity as part of the organisations basic mission, aims, objectives and strategic plans.

c. Management/leadership style: A style tending toward "participative" and away from "autocratic".

d. Commitment and involvement at all levels: Involvement of the individual and team at all levels of the organisation, with steering committees, a hierarchy of productivity committees and regular meetings of the management or executive committees involved in productivity. 
e. Communication: Extensive and open communication, particularly with regard to performance feedback with emphasis on that of the individual members of the organisation.

f. Technology exploitation: The use of technological solutions whenever necessary and justified on a costeffective basis. Technology is seen as something to be exploited for organisational and individual benefit.

g. Job security: Strong job security tends to encourage participation in productivity programmes.

h. High regard for human values: Organisations with good productivity records tend to have a high regard for human values, provide opportunity and reward for their people to be involved in innovation for improving productivity.

i. Broad perspective: The basic definition of productivity is viewed broadly, expanded to include more elements related to the objectives of the organisation, and focuses on results.

j. Concentration on high impact items: Items selected for attention are those which will have high impact and are sensitive to constructive change.

k. Planned Improvement and measurement: Planning for productivity improvement and the measurement of results is a routine function throughout the organisation.

I. "Ownership", responsiblilty and accountabllity: Clear ownership of aspects of productivity, together with responsibility for setting and achieving objectives, coupled to formal objectives for performance and improvement.

\section{STRATEGY FOR IMPROVING PRODUCTIVITY IN THE SADF}

From the foregoing a macro strategy for improving productivity in the SADF can be developed, one which meets the criteria for organisation-wide productivity and satisfies the needs of the SADF.

\section{TITLE}

For a variety of reasons some of which were mentioned earlier, the terms productivity, $Q W L$ and $Q A$ have developed somewhat adverse connotations in the SADF. In addition, the links beween productivity, industrial relations, morale and motivation need to be emphasised in some way.

In the interests of cultural acceptability, of linking productivity visibly to the aims of the CSADF and the other aspects mentioned, and of providing a link between the need for a professional SADF with professional military practitioners, it is recommended that a strategy for the improvement of productivity in the SADF be titled:

A strategy for Professional Military Management (Afr: Professionele Militêre Bestuur) with as its purpose:

\section{"To win the war, effectively and efficiently!"}

Sub-strategies for the Arms of Service could take on a personal, culturally acceptable flavour eg: Professional Naval Management.

\section{SYSTEMS MODEL OF STRATEGY}

Using the success criteria discussed earlier, aspects of the Total Quality Management programme (American Centre For Productivity and Quality. 1987)(TQM), DPAC, a strategy for developing the human resources of the SADF for the year 2000 (Eberlein,1990:38) and other elements, a systems model for the strategy has been developed at the second level of detail.

Appendix $A$ is a diagrammatic representation of the steps considered necessary to implement the strategy. This action flow diagram is a representation of the systems approach and depicts the action at the first level of detail. Each of the blocks (1.0; 2.etc) can be analyzed into greater detail as the implementation proceeds. The lines joining the various blocks have the 
direction of action flow shown by the position of the arrow near the junction of the lines. The final arrow at block 8.0 indicates the start of a feedback and evaluation loop, requiring the next action to be taken at block 1.0 ie the start of the system.

The model enables the reader to identify the eight main steps in the strategy (Appendix A), and then to identify the next level of detail within each step (Appendices $B$ to $H$ ). It also makes possible the placing into perspective "new" approaches and techniques with which the organisation is continually being bombarded eg $Q W L$, $Q A$, the "hints and suggestions system" and DPAC to name but a few.

Implementation of the system will need detailed reference to and development of plans suited to each level of detail. Each block (or step) can now be discussed.

\section{Step 1.0: Obtaln Top Management Leadership and Support}

Any strategy or proposal for improving professionalism (military management) must be supported actively by topmanagement, and must permeate the entire organisation. By leadership and support is meant not only verbal or mental acquiesence, but also the conviction that the strategy offered is the only acceptable one and active striving in a committed manner to make the achievement of its objectives possible.

Top management will need to become actively involved in activities aimed at achieving professional military management. They will need to go through the process of defining the vision, mission, aims and objectives and so on of the organisation as indicated in Step 1.1 .

Having done this they will need to demonstrate their leadership in acting as a role model,communicating their vision of professional management in the SADF, the mission, goals and values attached to such professionalism to individuals and teams in the organisation.
To do this, they (top management) will need to acknowledge professionalism (or professional military management) as a top priority and include it in all the objectives of their organisation.

The resources, time and training needed to make a success of professionalism need to be sanctioned and provided by top management, and included in the budgetary processes.

Of vital importance, given the present culture of the SADF, top management will need to create an organisation structure and culture which encourages and supports professionalism. The criteria for such an organisation include the aspects listed in Step 1.4 (Eberlein, 1990: ):

a. An Inspiring Leadership style attuned to the changing needs of the individuals eg participative and situation guided.

b. Supportive of innovation at all levels.

c. People orientation ie belief in and supportive of the individual as the most important single factor in any organisation.

d. Objectives which are not only realistic and attuned to the needs of the organisation and the members, but also which stretch the abilities of both.

e. Commitment by all members to the achievement of the objectives of the organisation.

f. Action orientation, ie determined to produce results, and concentrating on the achievement of them and not avoiding the issue in a variety of noneffective ways.

g. Simple in structure, so that the members of the organisation have clear lines of authority and communication which contribute to the easy achievement of the objectives.

h. A Co-operative organisation that is one in which cross-functional cooperation is a fact of life instead of the more usual internal competition. The former makes the functioning of the 
organisation easier, while the latter hampers it.

In order to foster professional management in all facets of the organisations activities, it will be necessary to identify and develop "ownership" of each facet or group of facets in individuals and teams. (note here the need to link this aspect to that of individual and team commitment (Step 5.0)). as part of developing ownership, not only should the roles of the owners be defined and the facets delegated to them but methods must be developed to reward performance which contributes to the achievement of professional management. More detail of this is suggested in Step 4.4 when innovative recognition and reward systems are dealt with.

The long-term commitment of management to the ideals of professional management needs to be nurtured. In all top managers, and especially in the SADF with its history of taksorientation and "instant solutions" accepting that some results will only become visible some years in the future is very difficult.

Such acceptance can be gained to some extent by producing "rounders" solutions to problems of high impact; while allowing more time for "cricket" solutions to the same problems. "Rounders" in this context means "roughand-ready" or instant solutions which meet the needs for short-term visible solutions. A "Cricket" solution is a scientifically-based solution requiring a great deal more research and possibly funding but specifically time, before an acceptable solution is found. Rounders permits cricket to be played and long term plans to be developed (Step 1.6).

Step 1.7 emphasises the need for management to be accessible to subordinates, and advocates the use of accepted management practices which make it possible. Here MBWA (Management by Walking Around) and open door policies are propagated. In addition the development and use of communication networks and other forums is indicated. Here, for instance, the use of internal mass media, tele- vision, periodicals, order groups, client forums and the like is vital.

Top management is normally the only level at which the major barriers to professional management can be removed. Barriers are those policies, practices, regulations, reward systems, attitudes, structures and systems and so on which prevent or hinder the individual or team in doing the job (Step 1.8). Although many of these barriers can be identified by top management, the usual and best procedure is to ask the individual concerned to do the identification ("What stops you from achieving the objective?") and then using top management to remove it. Under the barrier of attitudes attention would need to be paid not only to interpersonal problems and attitudes, but also to intergroup and individual problems (such as motivation and stress).

\section{Step 2.0: Integrate Milltary Profes- sionalism into Strategic Plans.}

Step 2.1 calls for the establishment of short and long-term aims and objectives for military professionalism (or professional military management). It is important that these should be linked visibly to the two aims of the SADF (Win the war, and Effective management) and that all Arms of Service, staff Divisions and other levels in the organisation should develop similar aims and objectives.

As with all objectives, they should meet the criteria of objectivity, measurability and validity. Proponents of the Management by Objectives system are fully aware of these criteria which are not strange to the SADF.

Two aspects which deserve special mention however are that these objectives should be budget-related (for without funds nothing can occur) and that they should be "high-impact, stretching" objectives. By "high-impact" is meant that for a relatively small effort, a resounding result of great value should be obtained a la the Pareto principle. By 'stretching' is meant that the objectives should be realistic and achievable but that they should require a great deal of effort to 
achieve, causing the individuals and teams to stretch to achieve them.

As is the usual procedure, action plans are then derived from the aims and objectives (Step 2.2) Of note though is that the procedure should be a formal one, that regular revisions and updates should be included in it and that the process should be based upon data, information and analyses obtained from the systems developed for collection and analysis (Step 6.0).

An unusual requirement for the SADF is that the needs and expectations of the client and the individuals in the organisation need to incorporated into the action plans.

Once the resources have been allocated (Step 2.3) using the normal systems in the SADF (hopeful more efficiently) reporting and review structures and procedures need to be established (Step 2.4).

In the past, the tendency in the SADF has been to establish special working groups and committees for this purpose. Hence the proliferation of eg Morale Advisory Committees, Image Advisory Committees and so on, which not only unnecessarily complicated the lives of Officers Commanding but also detracted from his authority and responsibility. It is advocated that reporting and review structures be incorporated into existing structures and committees, simply by adding the task(s) to the agendas of these groups. In this way networks can be developed to deal with the activities needed in order to achieve professional military management.

What is important though is that successes in this field should be publicised and recognition granted to individuals achieving those successes. In the area of publicity and recognition the SADF is particularly well-endowed, having many publications and methods of saying BZI (The Navy's way of saying "Well donel). Step 4.4 highlights some of the criteria for such recognition.

An important aspect is dealt with in Step 2.5: the need to adapt to environmental changes. So many changes are occurring with such speed in the environment in which the SADF functions that special attention needs to be paid to the effects thereof on the individual, the organisation structure and culture and adjustments made to cope with these affects. This is however, not a one-off activity but a continuous process of monitoring the environment and making adjustments.

\section{Step 3.0: Focus on the Client}

The output from Step 2.0 becomes the input for Step 3.0. Although the term "client" still falls strange on the SADF tongue, it is essentially a way of emphasising that activities need to be focused on the aims and objectives of the SADF. As the nearest representative of those aims is the "client" for whom the work is being done, activity needs to be focused on his (or her) needs, as derived from the aims and objectives of the SADF.

The series of steps in Step 3.0 move from determining the clients needs, selecting and sorting them in terms of impact and priority and specifying in measurable terms the end-results to be achieved or the services to be delivered.

If necessary, the process and structures need to be adjusted so as to be able to meet the needs of the client. By way of example: if the Subsistence and Transport (S\&T) penalises the client using the system, then it needs to be changed.

Client feedback is important here, and should be collected and used by the "owner" of the particular facet or problem. Some of the major changes made recently at the Personnel Division are a result of client feedback directly to the responsible owner (Step 3.5). The decentralisation of recruiting is a good example of this.

The concept of accessibility (Step 3.6) has already been dealt with, but this time accessibility between client and owner is meant.

The remainder of this step deals with the need to evaluate the feedback systems and the results achieved and 
adjust the processes to make the satisfaction of the clients needs possible.

\section{Step 4.0: Obtaln Commitment to Development and to Recognition of Performance}

In the SADF of the past it was largely taken for granted that the individual as a "good soldier" when given an instruction would carry it out to the best of his ability. Given the changing nature of the members of the SADF, the commitment of work and so on as detailed earlier (Eberlein, 1990: 36) such assumptions are no longer possible.

In order to achieve professional military management it is necessary to develop the skills of professional military management in individuals and teams, to ensure that they apply them, and then to recognise and reward their successful performance (Steps 4.1 to 4.6 ).

There is nothing new or strange in this except perhaps in the reward, incentive and recognition systems. Traditional methods (merit increases, promotion, medals and certificates) still have their (deserved) place, but new and innovative systems need to be developed to meet the new needs of the individuals. Methods whereby the individual is paid in cash or kind (a trip to Europel) for suggestions or savings are needed. Competitions with tangible rewards and recognition are the norm in the insurance and sales industry, and the people manning the SADF have the same needs and drives as their counterparts in the other industries.

A vital criterion though is that the rewards etc must be supportive of the aims and objectives of the SADF and not counter them.

Step 5.0: Obtain Individual and Team Commitment and Involvement.

Just as top management leadership is vital to the commencement and continuation of professional management, so is the commitment and involvement of the individual and the team to its final success.
A prerequisite to involvement and commitment is the provision of a supportive organisation structure and environment, as described earlier in Step 1.4.

Part of the support comes in the form of enhancing the authority and delegations to units and individuals in the form of decentralisation of authority to the lowest possible level. Enhancing this and ownerships, responsibility and accountability cannot however stop at giving this responsibility and authority. Many of today's employees (perhaps the majority) demand some form of reward for accepting extra responsibility. Responsibility and authority in themselves are not enough. Hence the query,"What's in it for me?" Some tangible form of enhancement, reward or incentive needs to be added to ensure success, as indicated in Step 4.4.

Although the SADF is not (yet) subject to the Labour Relations Act, the Trade Unions and Personnel Associations do wield a great deal of influence in the $S A D F$, and care needs to be taken to gain their support. In extreme cases, this support is a pre-requisite to the commitment and involvement of their members (Step 5.4).

Commitment and involvement do not come of themselves, and need to be developed. To this end there are a number of techniques and structures available which can be of use. Here is the place for development by teambuilding, by the introduction of peerpressure, of gain sharing, of quality circles and the like (Step 5.5).

In an organisation like the SADF which is structured on functional lines and where the different functionaries seldom come into contact with one another, ignorance of other functions and their needs is the norm. Professional military management demands cross-functional co-operation which in itself needs to be developed using the techniques and incentives already mentioned. Of use also are working groups with a multi-functional composition, social activities involving members of different parts of the organisation and so on (Step 5.6). 
Step 5.7 emphasises the need for the results of individual commitment and involvement to be measured. Here aspects such as the increase in suggestions made and accepted, improvement in $Q W L$ and $Q A$ can be used as measures of success.

However commitment and involvement are affected by circumstances, and the success of activities used to encourage commitment and involvement need to be evaluated from time to time and adjustments made to the strategy (Step 1.0) and the organisation structure and environment (Step 5.1).

\section{Step 6: Measure and Analyse Inputs, Processes and Outputs.}

Despite cries of outrage to the contrary, the activities of managers can be measured. This statement becomes even more valid when professional military management, as discussed in this paper, is subject to measurement.

The process starts with the identification and collection of meaningful data on end products and services emanating from the organisation. These data must meet the criteria of completeness, timeliness, accuracy and above all, usefulness. From the initial collection of these data, decisions can be made, on an iterative basis as to which data must be collected on an ongoing basis (Step 6.1).

From this systems can be derived or developed for the ongoing collection and analysis of data which meets the given criteria. Here systems such as the DPAC, the Unit Management Information system (UMIS; Afr:EBIS), the cost Management System, the matrix system of Fitz-enz (), the methodology of Dahl(1990) can be used to determine barriers to performance and the implications of specified actions taken (Step 6.2).

In the same way technology-based methods for identifying problems, and generating solutions as well as measures of effectiveness can be employed and used to correct deviations from the stated objectives and problem solutions. By way of example, there are a variety of computer-based packages for assessing the efficiency of transport usage. Such method might be employed off the shelf or slightly modified to determine the best routes to be followed by duty-buses. Here too, the need for a computer-based method for "keeping tabs on" progress and enabling acceptable solutions to problems to be copied ("Copy Cat) can be placed in perspective (Step 6.3).

\section{Step 7.0: Integrate Professionalism into} Continuous Improvement Programme

The outputs of Steps 3.0, 4.0, 5.0 and 6.0 form the input to Step 7.0.

The three sub-steps included here are aimed primarily at evaluation of success and comparing the results achieved with the needs, aims and objectives of the SADF and the clients. The results of the evaluation which should be based on the measurable criteria derived earlier, are then also used to determine how well the subsystems work. In practical terms one would evaluate for example:

a. The success of the DPAC system in highlighting problem areas in production of television programmes.

b. The ability of the EBIS to be used in reducing the indirect costs of running a unit.

c. The effects of changes to the personnel policies on motivation and morale.

d. The increase in QWL brought about by a change in the facilities provided in messes.

e. The increase in productivity in specified high-impact projects eg the pay system or the duty-bus system.

\section{Step 8.0 : Evaluate results and Adjust Strategy.}

Although this step is seen to be implemented only at the end of the full cycle, it is in fact something which takes place continually. Continual evaluation and adjustment is an integral part of the systems approach. What is needed here however is a total review (for example on an annual 
asis) of the successes achieved and he necessary reviews of all elements $f$ the strategy in order more nearly to neet the aims and objectives originally et.

\section{CONCLUSION}

this paper an attempt has been nade to propose a strategy for the nprovement of productivity and quality f work life which is acceptable to the ADF.

he aims of the SADF and the concept f productivity were examined and :ertain factors affecting productivity vere discussed.

$n$ this examination the relationships petween productivity, the quality of vork life,quality assurance, job perormance,motivation and morale, as vell as the management of industrial elations were defined.

he need for any productivity strategy o be culturally acceptable to the $A D F$ and the need to take into account ongoing productivity programnes were stressed.

The importance of professional management and the concept of a more orofessional SADF were used to define he role of the military practitioner.

The criteria for a successful productivity strategy were outlined and include the concept of a contingency approach and certain organisational criteria which are linked to the achievement of success in organisations.

From these aspecis a systems model of a strategy was developed, and it was proposed that the concept of Total Military Professionalism or of Professional Military Management be used to describe a strategy which incorporates all the factors affecting productivity in the SADF.

The systems model was then described to the second level of detail and the following eight main steps described:

Step 1: Obtain top management leadership and support.
Step 2: Integrate military professionalism into strategic plans.

Step 3: Focus on the client.

Step 4: Obtain commitment to development and to recognition of performance.

Step 5: Obtain individual and team commitment and involvement.

Step 6: Measure and analyse inputs, processes and outputs.

Step 7: Integrate professionalism into continuous improvement programme.

Step 8: Evaluate results and adjust strategy.

\section{A LAST COMMENT}

Although productivity is defined as the ratio of input to output, man is still the most important factor in improving productivity. Man is a complex, intelligent and sensitive animal needing to be treated as such before he (or she) will be able or willing to deliver of his best. Those in charge of productivity need to bear this in mind at all times.

* Rear-Admiral R. Eberlein S.D. DEd is Chief-Director Manpower Provisioning and Development, SADF.

\section{BIBLIOGRAPHY}

1. American Productivity and Quallty Centre, 1987. Total Quality Management, Houston Texas.

2. Ball,A. and Asbury,S.,1989. The winning way. Jonathon Ball Publishers, Johannesburg

3. Callahan, R.E., Fleenor, C.P. and Knudson, H.R., 1986. Understanding Organisational Behaviour. Charles E. Merrill Publishing Co., Columbus, Ohio.

4. Cronje, G.J. de J., Neuland, E.W. and Van Reenen, M.J., 1987. Inleiding tot die bestuurswese. Southern Book Publishers, Johannesburg. 
5. Dahl.T.,1990. Methodolgy. Tor Dahl and Assoclates, Minnesota.

6. Eberlein.R., 1990. The role of educational technology in the development of the human resources of the SA Defence Force for the year 2000. In Millitaria 20/3, SA Defence Force, Pretoria.

7. Ehlers, I., 1991. Arbeldsverhoudingebestuur en produktiwiteit., in Sake-Rapport 10 Feb 1991. Rapport, Pre-toria.

8. Fitzenz, J., 1987. How to measure human resources management. McGraw-HIII, New York.

9. Kulutbanls, M., 1990. Productivity management take-off. Productlvity Management Assoclates, Johannesburg.

10. Lehrer,R.N.2983. White collar productivity. McGraw-Hill, New York.
11. McAfee, R.B. and Poffenburger, W. 1982. Productivity strategies. PrenticeHall Inc., Englewood Cliffs, New Jersey.

12. Meeting of Productivity Co-ordinating Committee SA Defence Force; January 1991 (Personal Discussions).

13. Peters,T. and Waterman, R. H.,1982. Search of Excellence. Harper and Row. New York.

14. Project DYSAN,1989. Report submitted to the Chlef of the SA Defence Force, Pretoria.

15. Sutermelster,R.A.,1969. People and productivity. McGraw-Hill, New York.

16. Van Dyk, P.S.,1987. Die ontwikkeling van 'n organisasie-ontwikkelingstrategie vir die SA Vloot. Unpublished DCom thesis, University of South Africa. 


\section{SYSTEMS MODEL : A STRATEGY FOR PROFESSIONAL MILITARY MANAGEMENT}

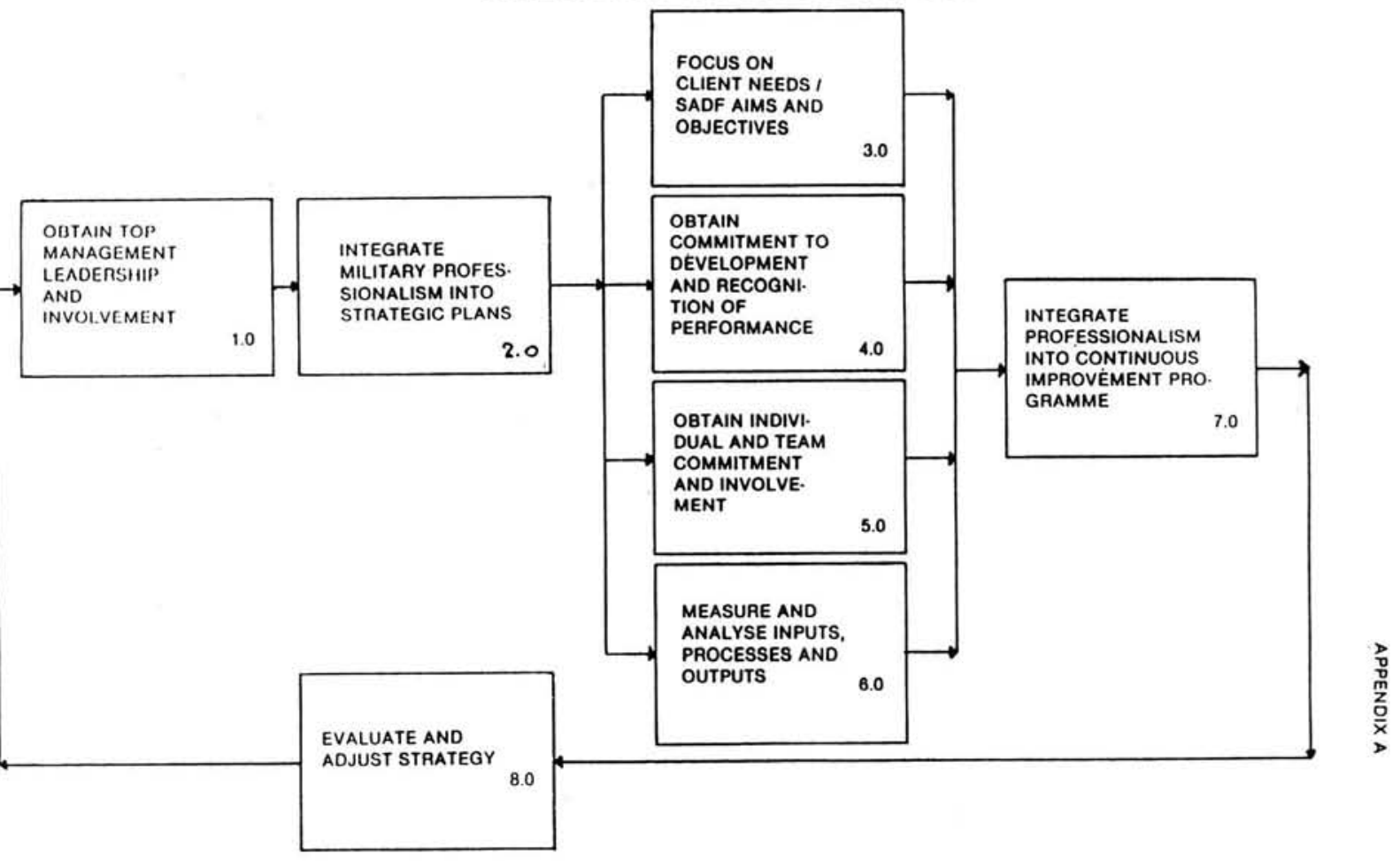

\section{OBTAIN MANAGEMENT, LEADERSHIP AND INVOLVEMENT}

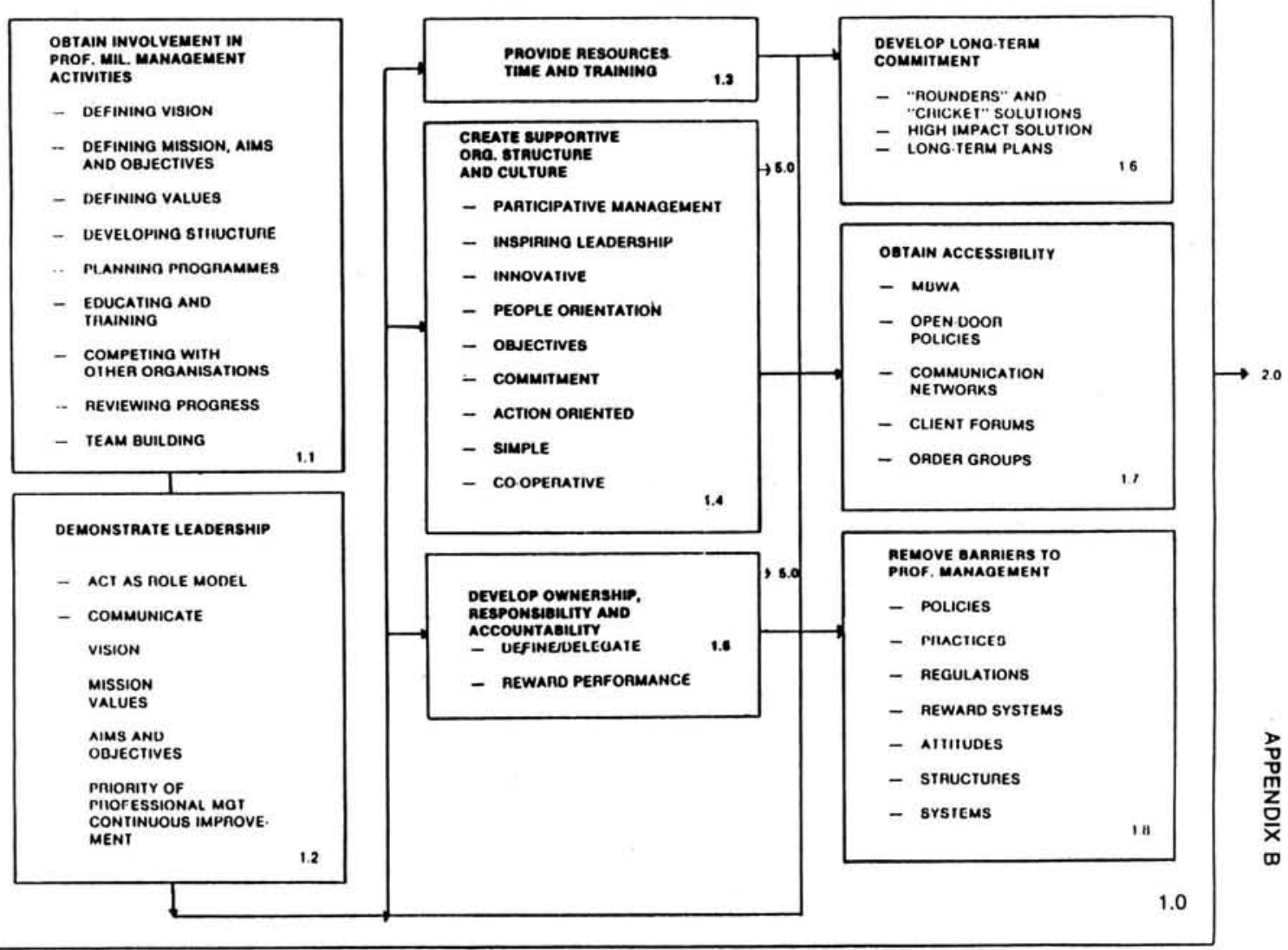




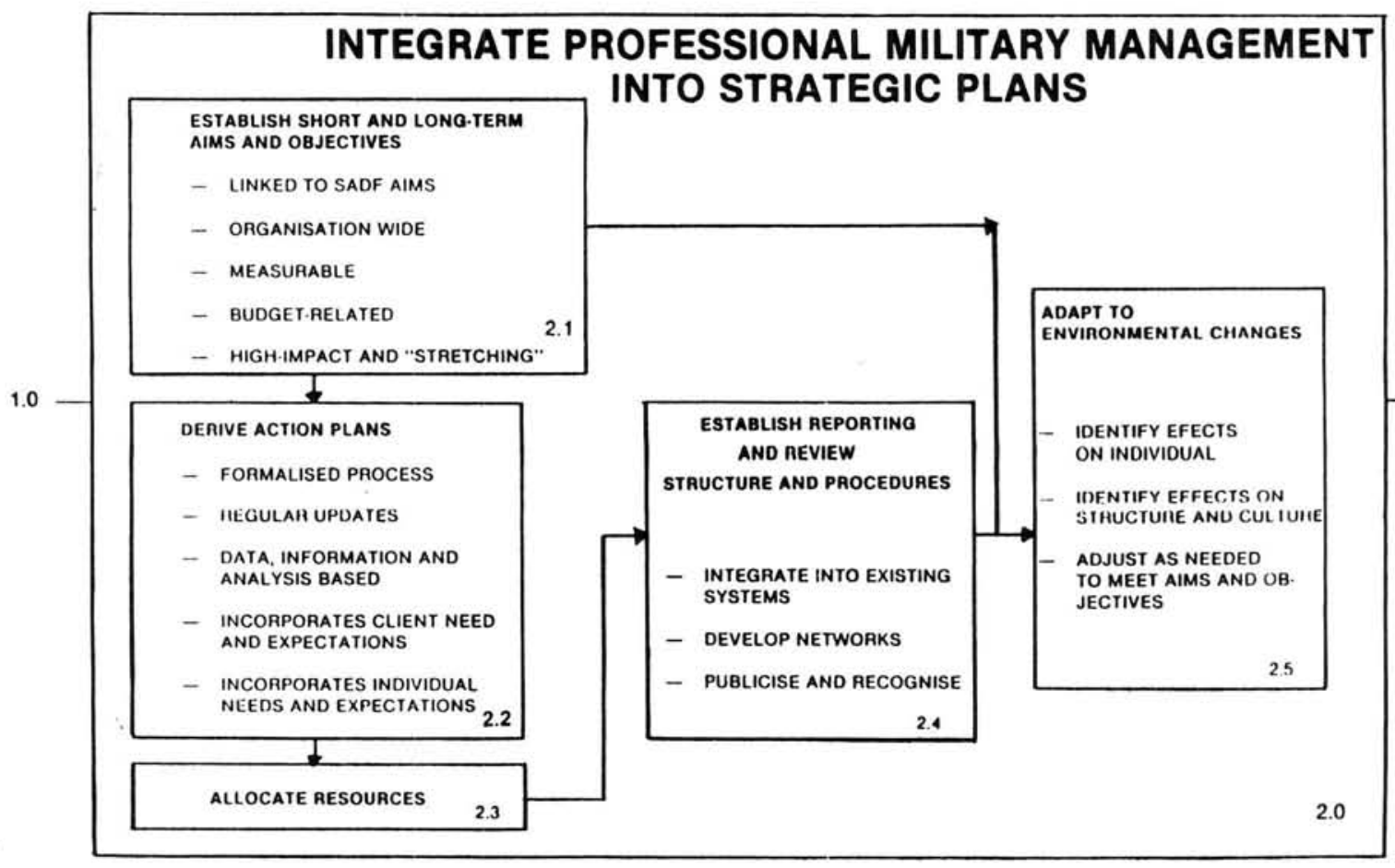

3.0

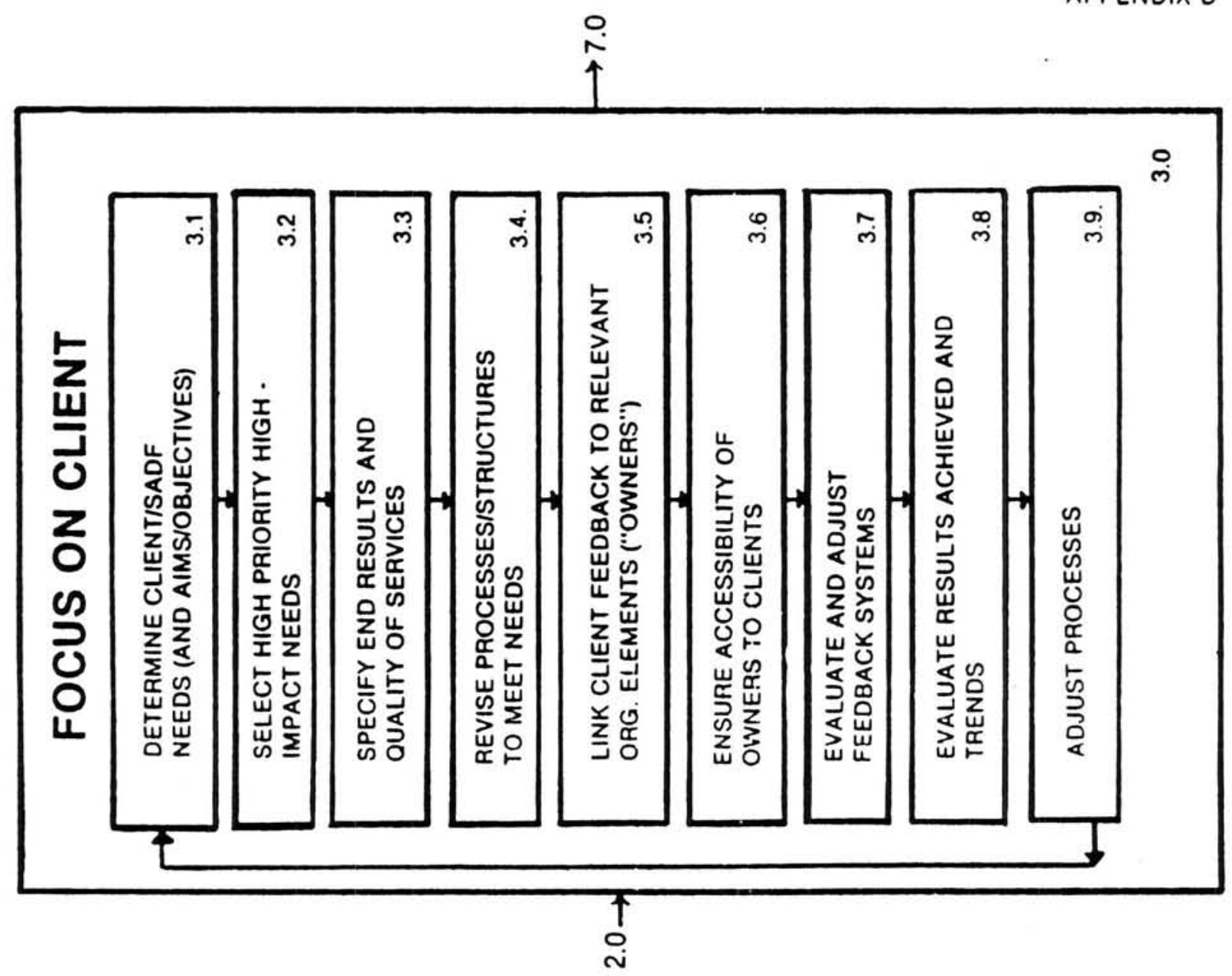


OBTAIN COMMITMENT TO DEVELOPMENT AND TO RECOGNITION OF PERFORMANCE

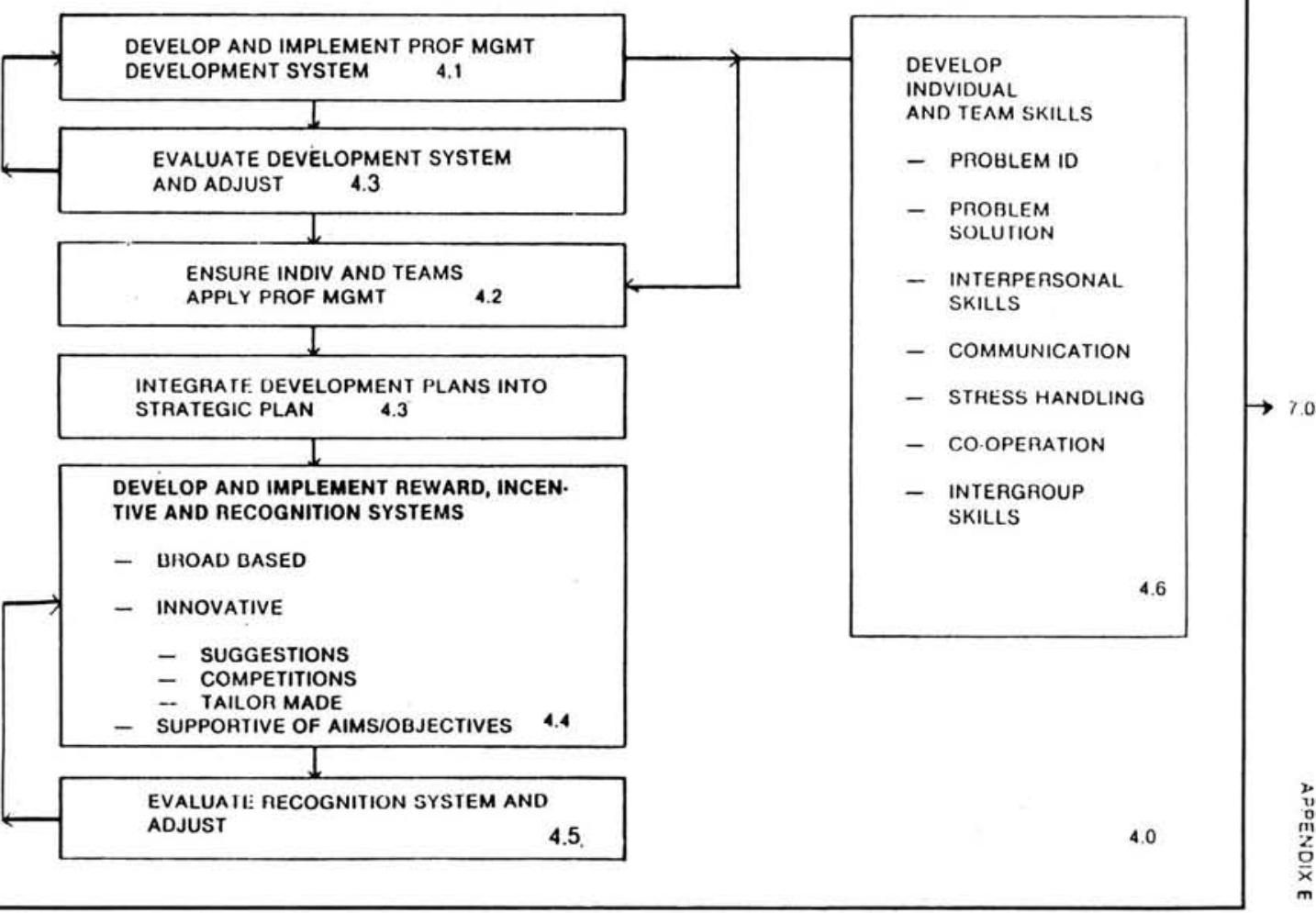

OBTAIN INDIVIDUAL AND TEAM COMMITMENT AND INVOLVEMENT

PROVIDE SUPPORTIVE ORG

STRUCTURE AND ENVIRONMENT

5.1

ENHANCE AUTHORITY + DELEGATIONS

TO UNITS, AND INDIVIDUALS

AT LOWEST LEVELS POSSIBLE

ENHANCE OWNERSHIP, RESPONSI. BILITY AND ACCOUNTABILITY

OBTAIN SUPPORT OF REPRESENTATIVE PERSONNEL ORGANISATIONS

(EA PSA, PSL ETC)

DEVELOP INNOVATIVE INVOLVEMENT PROCESSES

- team-BUILDING

- PEER ASSESSMENT

- STRESS RELIEF

- GaIN SHARE

- quality ciRcles

- MERIT INCREASES

- AWARD SYSTEMS
DEVELOP CROSS.FUNCTIONAL TEAM CO.OPERATION

- TEAM BUILDING

- WORK GROUPS

- SOCIAL ACtIVITIES

DEVELOP AND IMPLEMENT

SYSTEMS FOR MEASURING

INDIVIDUAL AND TEAM

COMMITMENT

SUGgESTIONS

ACCEPTANCES ETC

- QWL IMPROVEMENT

- QA FIGURES

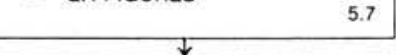

EVALUATE SUCCESS AND

ADJUST ACTIVITIES

FOR CONTINUED COMMITMENT

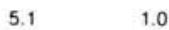



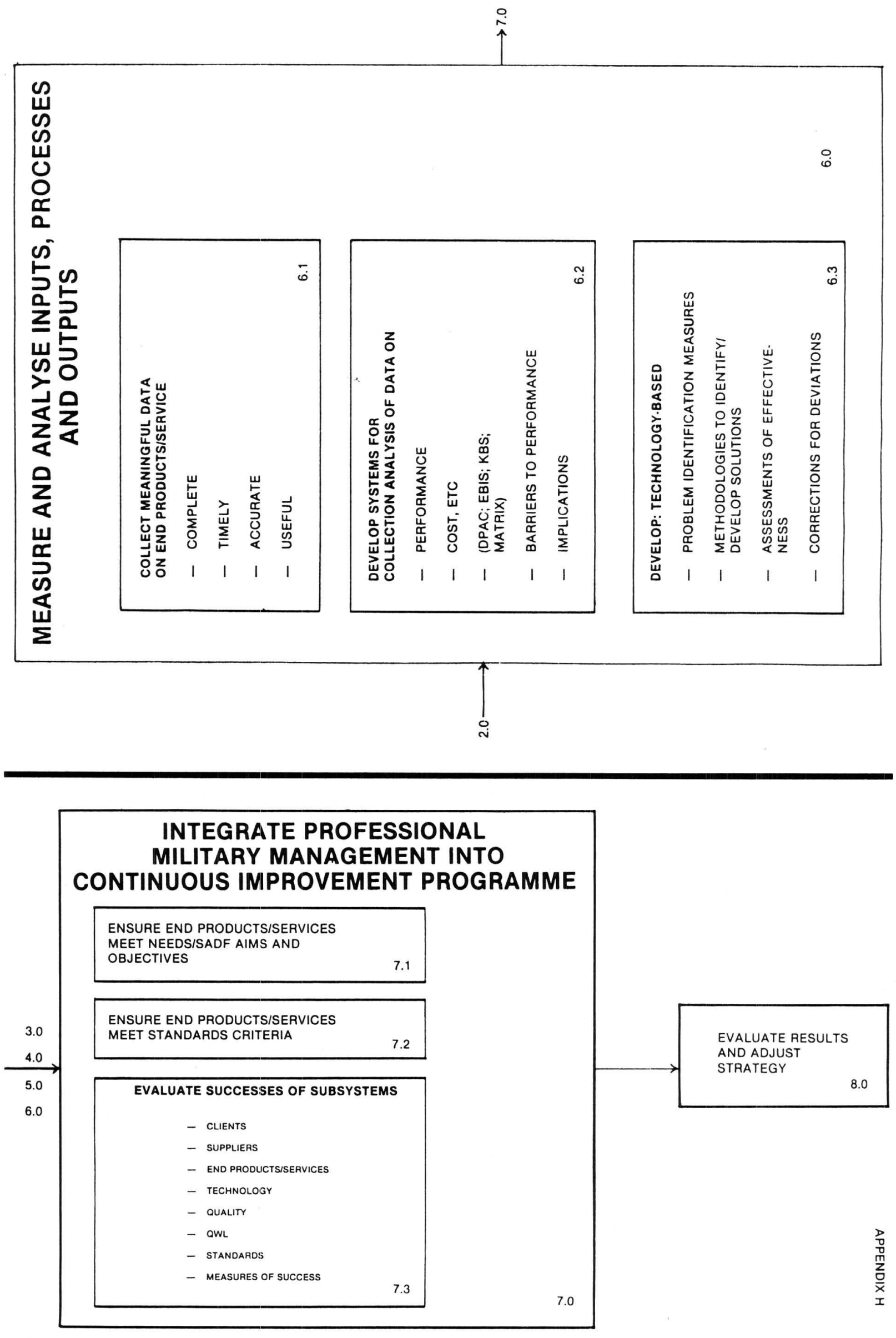